\title{
TECNOLOGIAS CONFESSIONAIS: CORPOS QUE SE FAZEM NAS VIRTUALIDADES
}

\author{
Alexandre Luiz Polizel ${ }^{1}$, Moises Alves de Oliveira ${ }^{2}$ \\ ${ }^{1}$ Universidade Estadual de Londrina - UEL, Programa de Pós-graduação em Ensino de Ciências e Educação \\ Matemática, Londrina, PR. ${ }^{2}$ Universidade Estadual de Londrina - UEL, Departamento de Química, Londrina, PR. E- \\ mail: alexandre polizel@hotmail.com.
}

\section{RESUMO}

Compreendendo a produção de saberes e dos corpos como proposições e composições das práticas culturais, nos colocamos neste manuscrito a pensar as constituições dos corpos e corporalidades no ciberespaço. Este, contudo, é parte de uma investigação maior de dissertação, desenvolvida no Programa de Pós-graduação em Ensino de Ciências e Educação Matemática da Universidade Estadual de Londrina. Assim, temos por objetivo, neste trabalho, traçar considerações acerca das tecnologias confessionais como instrumentos de corporificação e virtualização dos corpos. As considerações são levantadas a partir do referencial teórico de inspiração nos Estudos Culturais das Ciências e das Educações e das contribuições deixadas por Michel Foucault. Nos apropriamos de tais teorizações, na produção de lentes analíticas, que nos auxiliam durante o processo de imersão antropológica realizada em um grupo-espaço da rede social facebook, identificada aqui como Vale. Esta imersão movimenta-se a fim de indagações sobre múltiplas ontologias dos corpos, sendo utilizado neste manuscrito, o conceito de tecnologias das confessionalidades. Evidenciamos no grupo, regimes confessionais atuantes por: a) Confissão de micro-histórias, em publicações, como modo de narrar a si; b) Convites às confissões como operante de agenciamento das vontades e produção de arquivos; e c) Resposta aos convites, à confissão.

Palavras-chave: Corpo, Confissão, Ciberespaço, Redes sociais.

\section{CONFESSIONAL TECHNOLOGIES: BODIES THAT DO IN VIRTUALITIES}

\begin{abstract}
Understanding the production of knowledge and bodies as propositions and compositions of cultural practices, we place ourselves in this manuscript to think about the constitutions of bodies and corporealities in cyberspace. This, however, is part of a larger dissertation research, developed in the Graduate Program in Teaching Science and Mathematics Education of the State University of Londrina. Thus, we aim, in this work, to draw up considerations about the confessional technologies as instruments of embodiment and virtualization of the bodies. The considerations are raised from the theoretical reference of inspiration in the Cultural Studies of Sciences and of Education and the contributions left by Michel Foucault. We appropriate such theorizations in the production of analytical lenses, which help us during the process of anthropological immersion carried out in a group-space of the facebook social network, identified here as Vale. This immersion moves in order to inquire about multiple ontologies of the bodies, being used in this manuscript, the concept of technologies of confessionalities. We show in the group, confessional regimes that are active by: a) Confession of micro-stories, in publications, as a way of telling oneself; b) Invitations to confessions as operant of agency of wills and production of archives; and (c) response to invitations to confession.
\end{abstract}

Keywords: Body, Confession, Cyberspace, Social nets.

\section{NOTAS INTRODUTÓRIAS}

Este manuscrito consiste em um recorte de uma investigação maior desenvolvida como parte constituinte de dissertação no Programa de
Pós-graduação em Ensino de Ciências e Educação Matemática da Universidade Estadual de Londrina. Trabalho movido por inquietações, que nos deslocam pelas tessituras do pensar: "Como 
corpos se constituem na virtualidade?" lançamo-nos, neste manuscrito, do instrumental conceitual da tecnologia da confissão explanado por Michel Foucault (2015; 2014a) para traçar considerações acerca desta problemática. É esta indagação que nos movimenta, levando-nos a voltar nossos olhares à rede social facebook como território e, em específico realizamos uma imersão antropológica em um grupo ${ }^{1}$ voltado ao público jovem, composto por 953.096 membros $^{2}$, que se (auto)identificam como pertencentes do "Vale" ${ }^{3}$.

Este grupo é selecionado por interesses e conveniências, visto que um dos pesquisadores já encontrava-se imerso neste espaço desde sua criação, realizada em agosto de 2013. Voltado a ser um espaço de humor e acolhimento a pessoas do "Vale", a escolha de tal grupo foi impulsionada pela potencialidade sentida neste espaço, pelo investigador-participante, que à época, não tinha sua questão de investigação bem definida, mas já via no grupo a operação de uma tecnologia da confissão.

O que é tratado como tecnologia da confissão neste manuscrito emerge a partir da óptica dos Estudos Culturais das Ciências e das Educações, afinado a um olhar Foucaultiano (FOUCAULT, 2015; 2014a; ARTIÉRRES, 2004; MARTINS, 1998). Para Michel Foucault (2015; 2014a), as técnicas, téknes, são modos de produção, de articulação entre enunciados e agires e, assim, inaugura sempre novos modos de existência em sua operação. Estas técnicas desenvolvem-se articuladas a instrumentais, a tecnologias, que centram-se em um conjunto de ferramentas e instituições, que colocam as técnicas em operação. Tais tecnologias alinhamse então na produção, via mecanismos de criação de sentidos, técnicas de poder que operacionalizam processos de subjetivação e, técnicas de resistência, que resistem, deslocam, torcem, destorcem e fraturam as técnicastecnologias de poder.

\footnotetext{
1 Não citamos o nome do grupo neste manuscrito visando a preservação da identidade deste espaço e dos sujeitos presentes neste. Com a finalidade de criar um quadro de referências, utilizaremos no texto completo recortes (prints) contendo o conteúdo das postagens.

${ }^{2}$ Números de membros contados no dia 10/04/2018

${ }^{3}$ Esta categoria identitária é utilizada pelos próprios membros, sendo referência ao espaço condenado pela instituído doutrina cristã, o "Vale dos Homossexuais". Desta forma o termo é utilizado como instrumental de contracondutas, ressignificando a condenação cristã do "vale" e afirmando a si como membros das diversidades sexuais que ocupam este espaço com vida, alegria e deboche.
}

Michel Foucault (2015) coloca-nos a pensar, em a História da Sexualidade 1, a tecnologia da confissão, como um modus operante de produção de si e dos outros, via o ato de confessar. Esta tecnologia torna-se possível à medida que a confissão torna-se uma técnica valorizada para a produção das verdades. No Ocidente, "Confessa-se - ou se é forçado a confessar" (FOUCAULT, 2015, p.66), pois assim, produz-se uma verdade de si e do Outro, para si e ao Outro.

A própria produção do homem seria um instrumental que possibilitasse o exame e a confissão deste corpo, pelas Ciências da Vida, Ciências Econômicas e Ciências Humanas (FOUCAULT, 1999). A alma, um produto do ato de confessar-se, busca tornar-se substância em movimento pelo virtus, instituído pela súmula teológica cristã. $\mathrm{O}$ ato de confessar encontra-se centrado no enunciar o que examinou de si, e este confessar é tomado como verdade, à medida que marca o corpo e a alma daquele que decide enunciar a si em espaçamentos públicos e/ou sacrais.

Destarte, minha primeira ferramenta conceitual, para buscar sugestões referentes a "Como o corpo produz-se na virtualidade?", provém do olhar a tecnologia da confissão. Já sentia essa produtividade nos ciberespaços, com uma impressão de que as confissões eram estimuladas (FOUCAULT, 2015; 2014a) e o corpo só fazia-se ao confessar, deixando registros de si. Todavia, gostaria de analisar quais eram os modos em que estas tecnologias da confissão encontravam-se operando. Da análise desses modos de operação, destacarei três como eixos analíticos que guiam este manuscrito: a) Confessando em micro-historiografias; b) Convidando outros a confessarem-se; e c) Respondendo aos convites da confissão.

O que demarcamos nestes três eixos, é a potencialidade de uma leitura sobre os deslocamentos das tecnologias de confissionalidade como um dos modos de existência possíveis para leitura de corpos que produzem-se na virtualidade, sendo uma herança das narrativas-relatos de si da antiguidade e, das tecnologias de examologêsis e exagoreusis desenvolvidas na idade média-moderna. Assim, o presente trabalho utiliza esses três eixos como fios condutores a serem explanados no desenvolvimento deste manuscrito. 


\section{VOLTANDO NOSSOS OLHARES AO VALE}

Ao pensar como um corpo produz-se, fazse, nas virtualidades, necessitamos inclinar nosso olhar a algum território, algum espaço, para refletirmos em como ele se constituía em relações contingenciais das práticas culturais. Ao compreendermos a virtualidade, de acordo com Pierre Lévy (1996), não consiste pensarmos em um falso oposto da dicotomia com o real, mas sim, uma relação contingencial com o tempo. Para pensar assim, Pierre Lévy recorre a filósofos clássicos e medievos, mais especificamente a Aristóteles e São Tomaz de Aquino. Assim, o mesmo pontua que o virtual consiste em uma relação de espaço-tempo com a atualidade, desta forma: a virtualização opera como um complexo problemático, um processo que possibilita um desprendimento do aqui e agora, um ato de desterritorialização que rompe com os limites epistêmicos vigorantes que definem espaçotempo, e arrasta este coletivo a uma localização "não presente", mas localizável. Enquanto a atualização, vem como uma criação, uma invenção em relação ao complexo problemático da virtualização, de modo que criativamente, acessa-o, presentifica-o e atribui ao virtualizado uma localização. Tanto a virtualização quanto a atualização dão-se sob movimentos articulatórios, em uma agonística constante de desterritorializar e territorializar.

Assim, elegemos um espaço, por conveniência, ao compreende-lo como um espaço produtivo para operarmos com nosso bisturi, a tecnologia da confessionalidade. O espaço que direcionamos nossos olhares foi a rede social facebook, como território, mais especificamente a um grupo em que foi realizada uma imersão antropológica, desde 2013. O grupo consiste em um espaço que propõe-se ser voltado ao público jovem, composto por 953.096 membros, alinhados aos movimentos de pródiversidade e de direitos humanos e, que se autoidentificam como pertencentes do Vale. $\mathrm{O}$ Vale $^{4}$, neste sentido, tem como referência o Vale dos Homossexuais - espaço instituído na

\footnotetext{
${ }^{4}$ Esta investigação se da tendo como base a Resolução no 510, de 7 de abril de 2016; sendo que a analítica desenvolvida neste trabalho tem por finalidade aprofundamentos teóricos que emergem espontânea e contingencialmente da prática profissional e de fenômenos cotidianos, comprometendo-se com a não identificação dos sujeitos - não sendo então avaliada pelo Comitê de Ética e Pesquisa. Assim, atribuímos ao grupo um nome fictício e, removemos as possibilidades de identificação dos indivíduos envolvidos no processo investigativo (como nomes, fotografias pessoais, endereços eletrônicos e até mesmo imagens de pessoas públicas presentes nas postagens).
}

discursividade de vertentes cristãs que apontam este como território de sofrimento e condenação às pessoas que vivessem prazeres homoafetivos ${ }^{5}$. A produção deste espaço-território, consiste em uma atitude cínica do grupo, de (res)significar o Vale por meio de um cinismo, do ato debochado de colocar em dúvida o estatuto de verdade eleito pela vertente cristã, centrado nestes casos na condenação e negação de modos de existir.

Ao imergirmos no grupo, buscamos a utilização de uma lente analítica, valendo-nos da perspectiva do "Diagnóstico do Presente", ancorada nos estudos de Michel Foucault (2015; 2014a; ARTIÉRRES, 2004; MARTINS, 1998), considerando aspectos genealógicos, voltados à recusa de uma ideia de origem, bem como centrados nas noções de proveniências e emergências de corpos que fazem-se. Proveniências que consideram a inexistência de categorias de semelhança e continuidades e, inclinam-se a observar marcas sutis, singulares e produtoras de diferenças - do corpo que se relaciona consigo mesmo. Assim, se o corpo articula-se consigo mesmo e produz diferenças, este articula-se em um contexto histórico, localizado e, portanto, emerge-se desta articulação.

Destarte, ao voltarmos nossos olhares às marcas e aos rastros do corpo e no corpo, mostra-se um caminho possível para (re)presentifica-los e refletir sobre a (des)(re)produção deste. Neste tocante, o diagnóstico do presente utiliza de instrumentais cirúrgicos para cortar, examinar e diagnosticar o presente, a pensa-lo e a movimenta-lo, para pensar a existência. Para isto utilizamos os conceitos de confessionalidades, tecnologias e (auto)disciplina (FOUCAULT, 2015; 2014a) e sua hibridização em uma "tecnologia das confessionalidades".

Estas tecnologias operam por meio de técnicas, téchne, téknes, que são processos de criação, de produção, de novos possíveis - e também de novos impossíveis, Considerando que as mesmas são centradas em organizações discursivas (saberes colocados em movimentação e que mantêm-se ao reverberar-se e rarefazer-se)

\footnotetext{
${ }^{5}$ Utilizamos o termo homoafetividade, compreendendo que estas religiões identificam os modos de existência gays, lésbicos, bissexuais e de pessoas trans como relações homoeróticas/homoafetivas. Assim, ao usarmos o termo homoafetividade fazemos com o intuito de que este abranja as múltiplas categorias identitárias, pertencentes as minorias sexuais, que desviam-se de operar sob uma lógica de uma identidade heteronormativa.
} 
e não discursivas (arquiteturas, instituições, organizações do espaço, ferramentas).

Estas criações produzem também valorações, elegendo modos de conduta passíveis de serem vividos, em detrimento a outros. Estes modos de conduta são aprendidos, afetam o corpo, produzem uma subjetividade neste e, colocam-o para operar seguindo sua lógica. Como determinados modos de ser são mais valorizados que outros, estes são estimulados, buscam desenvolver maior expressividade destes modos, disciplinam o corpo a agir de determinada forma - o corpo é disciplinado. Em determinados momentos, necessitam-se das instituições para que a disciplina opere: família, escola, igrejas, bairros, hospitais, livrarias... Instituições que disporão a organizar espaços-tempos, saberespoderes-verdades, e a direcionar as experiencialidades (im)pulsionando o regime de verdade vigente. Para que o corpo opere por esta lógica - dispõe-se então de mecanismos de vigília para conferir se a ordem encontra-se vigente de acordo com o regimento. À medida que o corpo disciplina-se, não é necessário mais o outro que observa; o próprio corpo subjetivado, tornado sujeito, observa a si próprio. Todos observam-se e ninguém observa ninguém, este é $o$ ato de autodisciplina ou, autogovernamento.

Neste sentido, a confessionalidade encontra-se em um território fértil, o espaço em que o sujeito deve olhar constantemente a si mesmo, examinar a si constantemente, e enunciar sempre que convidado àquilo que vislumbra. Este enunciar os produtos do exame de si é o ato de narrar a si. Esta narrativa de si, à medida que busca uma verdade, que cristaliza um modo de ser e busca redenção, ou valoração por este, é um ato de confissão. A tecnologia de confissão, neste sentido, teria em suas bases a tecnologia, a (auto)disciplina e a confessionalidade - como um modo de produzir existências. Vislumbramos no grupo três modos de confissão: Confessionando microhistoriografias; Convite à confissão; e as Respostas aos convites de confissão. Outros modos poderiam ser considerados, mas enfocaremos estas três operações.

\section{CONFESSIONANDO MICRO-HISTORIOGRAFIAS}

Como já dito antes, o ato de confessar consiste em uma derivação do narrar a si. Poderíamos dizer que Michel Foucault (2015; 2014a) realiza uma genealogia do narrar a si, retornando a escolas gregas como a estóica e o hedonismo, bem como fazendo um recorte de como esta tecnologia - do narrar a si - toma outros contornos durante a idade médiamoderna e a contemporaneidade. A narrativa de si, neste trabalho é tratada como uma técnica de si, como produções de modos de subjetivações negociados, entre poderes e resistências a discursividades regentes - técnicas regidas nas trações dos jogos de verdades. Ao retomar seu olhar às narrativas de si, Foucault confere uma característica a elas: o olhar do exame a si. Este exame de si centralizar-se-á no olhar a sua rotina, seus comportamentos, suas condutas, no voltar os olhos para si mesmo.

Ainda, para Michel Foucault (2014a), o ato de narrar a si na antiguidade e, o próprio desenvolvimento de múltiplos modos de pensar desta época, centravam-se na preocupação com a técnica, da técnica do cuidado de si epimelesthai seautou. A exemplos disso são trazidas três técnicas, características da filosofia histórica, que refere-se ao narrar a si como técnica de si voltada ao cuidado de si, sendo: "[...] as cartas aos amigos e o que elas revelam de si; o exame de si mesmo e de sua consciência, que compreende a avaliação do que foi feito; e a comparação dos dois" (FOUCAULT, 2014a, p.281). Processos ritualísticos, atos contínuos, askesis, a revelação de uma lembrança a si que recorre ao narrar a si para si mesmo - processos íntimos, entre si mesmo ou entre amigos, que buscavam verter-se sobre seu desejo, não para renuncia-los, mas para uma afirmativa de si pautada no cuidado.

Os ideais de narrar a si cristãos colocamse em outro plano. As vertentes cristãs desenvolvem uma relação entre a verdade de si e a salvação e, só pode recorrer à verdade em processos de purificação. Neste sentido, o conhecer a si é importante a fim de estabelecer uma política de governamento - de si e dos outros - em que o cuidado segue outro quadro de referências, centrado no narrar a si publicamente, renunciando as vontades do eu que estivessem em dissidência com o regime cristão. A purificação centrar-se-ia na renúncia e, a narrativa de si passaria das intimidades para a publicidade do eu. Duas técnicas desenvolvem-se na episteme cristã: a) Exomologese, voltada ao reconhecimento público da verdade de sua fé cristã, reconhecendo-se como pecador ou como penitente, marcando seu corpo à brasa, se necessário - ato teatral de reconhecimento; e b) 
Exagoreusis, focalizada na verbalização constante de seus pensamentos e testemunhos.

Assim, tanto nas vertentes estóicas, quanto judaico cristãs, o narrar-se tinha um estatuto de operação centrado na produção de uma verdade sobre si e em relações de cuidados. Ou no âmbito do íntimo, ou no âmbito do público. Ou enfocava-se em um cuidado exame, para um cuidado enfocado nas vontades singulares do si, ou enfocava-se em um cuidado pautado em seguir um quadro de referências e em renunciar seus desejos singulares. Ou na investigação de si via téknes de registros e exame de si consigo mesmo, ou na confissão constante, teatral e de penitencialidades...

Evidenciamos no grupo estudado uma hibridização destas possibilidades, uma focalização na publicidade de si, uma teatralidade do confessar-se em público e reconhecer tal ato narrativo como um processo de produção de verdade de si. Isso os conduz a algo que hibridiza a uma "suposta" intimidade deste espaço, que não seria mais nem público e nem privado, mas um coletivo de colegas, condenados pelos mesmos atos - um espaço Vale dos homossexuais. Neste sentido, o efetuar uma postagem, criar uma narrativa que confere uma suposta verdade ao seu $E$, borra fronteiras do espaço-tempo. Este espaço seria intimo ou público? ela confessa a amigos ou a sujeitos de sua mesma religião? Esta é uma técnica ou ela segue uma moralidade vigente, característica de uma subjetividade contemporânea nos ciberespaços? ... Uma multiplicidade de possibilidades faz-se evidente e levanta indagações para movimentar a substância pensamento.

O Vale torna-se íntimo-público, quartofacebook, para amigos-religiosos, técnico-moral. É uma confessionalidade, no sentido que produz um reconhecimento de si e torna-o publicidade de si e é cuidado de si à medida que volta o olhar a si mesmo e possibilita uma reflexão sobre suas vontades - permitindo que o outro que conectase a este também reflita sobre si. É confessar-se constantemente, mas também o examinar-se em horários específicos.

Estas confissões, estes modos de confessar-se e criar-se que compõem o que aqui é chamado de uma tecnologia da confissionalidade, dar-se primeiramente pela possibilidade de produzir micro-histórias sobre si. Veja um dos recortes (FIGURA 1) retirados do Vale, nosso espaço de construção e imersão: 
Figura 1. micro-historia ${ }^{6}$

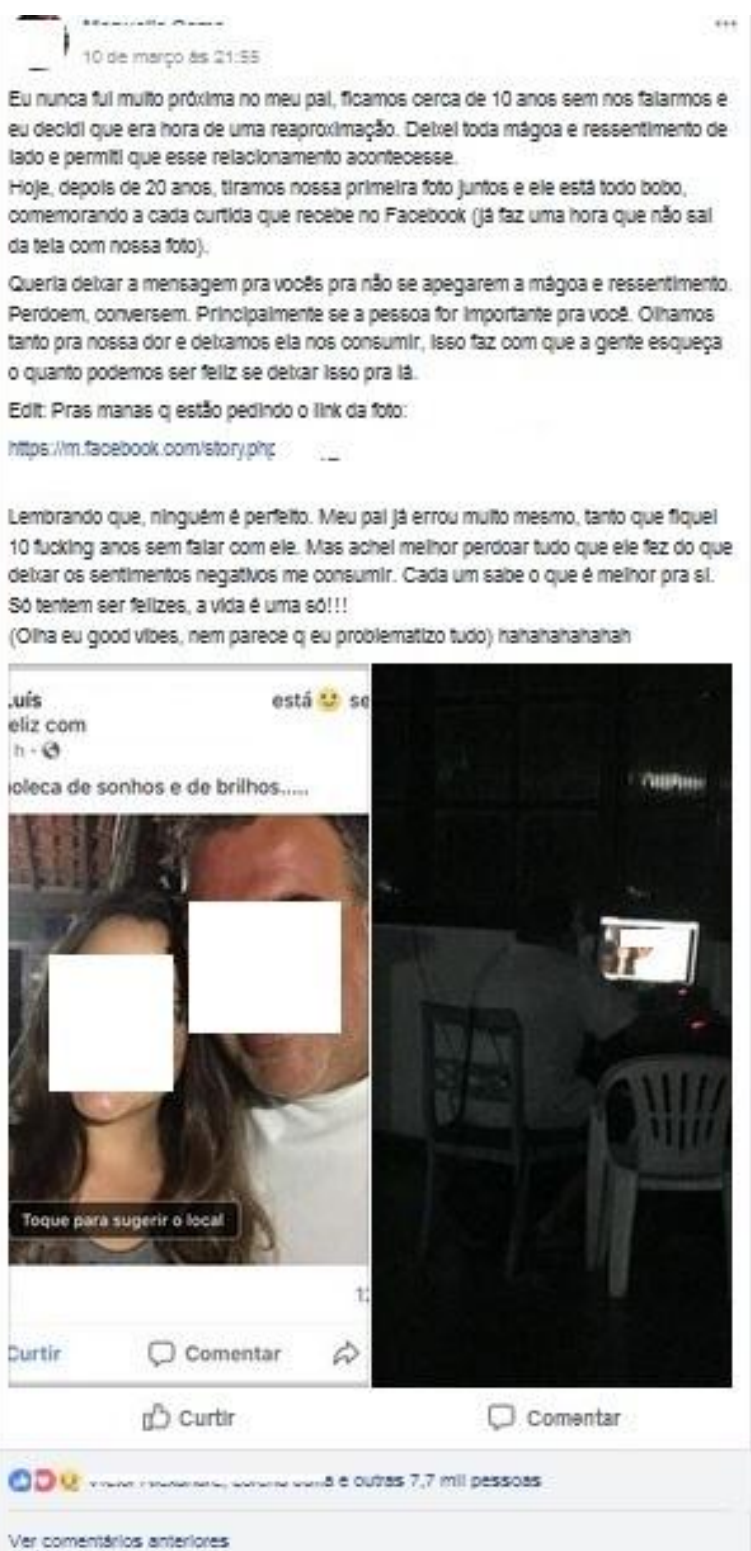

\footnotetext{
${ }^{6}$ As figuras presentes neste manuscrito consistem em recortes do grupo estudado, assim, todos os marcos que permitissem a identificação das pessoas ou do grupo foram removidos.
} 
Nota-se que a produção de microhistórias, registros de um ato acontecimental, é característico também no narrar a si da antiguidade grega - mais especificamente um exercício estóico de exame e cuidado de si - e, nos processos de exomologese e exagoreusis, o que garante um vínculo de enunciados e técnicas que conferem, a estes modos de narrar a si, produzirem substratos para a produção de uma tecnologia da confessionalidade contemporânea. Todavia, pode-se evidenciar diferenciações no processo de produção, na criação de outros modos, nas téknes. Michel Foucault (2014a) evidenciava nos estóicos a utilização de cartas entre amigos os registros de Senêca e, de diários íntimos dos Hypomnêmata, como instrumentais que possibilitavam a produção de uma técnica de exame de si. O mesmo aponta também para a utilização teatralizada de confissões públicas, de penitências e marcações dos corpos, do exercício de confessar-se continuamente no entorno das camarinhas e sessões coletivas, como gerenciadores do narrar a si na experiencialidade cristã.

$\mathrm{Na}$ tecnologia da confessionalidade, realizada nos ciberespaços, outras técnicas são mobilizadas para garantir a produção da narrativa em micro-histórias. Utiliza-se do uso da escrita, de fotografias, vídeos, da disposição de links que criam um direcionamento a outras páginas - a escrita de si, no que tocam as micro-histórias, passam de uma perspectiva de escrita em cartas ou diários, ou de uma "escrita oralizada" para uma escrita de si em hipertexto. Essa escrita de si hipertextual, consistiria compor-se em blocos, garantindo uma maior possibilidade de composição narrativa que garantisse veridicidade e, a possibilidade de novos possíveis por congregar mais instrumentais no desenvolver desta outra tékne, de novos possíveis. A produção de uma confissão em micro-histórias ganha assim uma amplitude das potencialidades
- agora também com possibilidade de edição dos hipertextos.

\section{CONVITES À CONFISSÃO}

Ao pensarmos na produção de relatos narrativos, de mobilizar micro-histórias no processo do confessar-se e constituir-se, temos apenas um dos processos do que tratamos como uma tecnologia da confessionalidade - que seria $o$ ato do confessar-se. Todavia, outros operantes são mobilizados nos ciberespaços, que não enfocam a necessidade de produzir uma narrativa sobre si, mas sim, uma necessidade de convidar o outro a falar sobre si e a produzir-se.

$O$ ato de confessar nunca envolveu apenas um cuidar-se de si, mas sempre considerou que um cuidar-se de si centrava-se também em um cuidado com o Outro. Os atos narrativos estóicos envolviam aconselhamentos, reconhecer-se, examinar a si e isto era sempre realizado em quadros de olhar também o Outro. As cartas a Sêneca envolviam processos de aconselhamentos, de indagações sobre as condutas - e nas indagações as aberturas a outros modos de pensar, que não apenas os que encontram-se evidenciáveis. Nos processos confessionais, de exame de si, das religiões - e podemos estende-los aos exames de si produzidos pelos discursos jurídicos, médicobiológicos e pedagógicos - existia uma preocupação com o Outro, a preocupação de que estes operassem de acordo com um quadro de referências vigente, segundo uma referência de normalidade e/ou de pureza (FOUCAULT, 2015; 2014a). Assim, um dos processos indispensáveis do apanhado das tecnologias de confessionalidades, são os convites à confissão.

Vemos uma interação que é frequentemente mobilizada no Vale, o ato de confessar a todo momento e de estimular o outro a confessar-se. Observem a figura (FIGURA 2) abaixo: 
Figura 2. Convidando os outros a confessarem-se

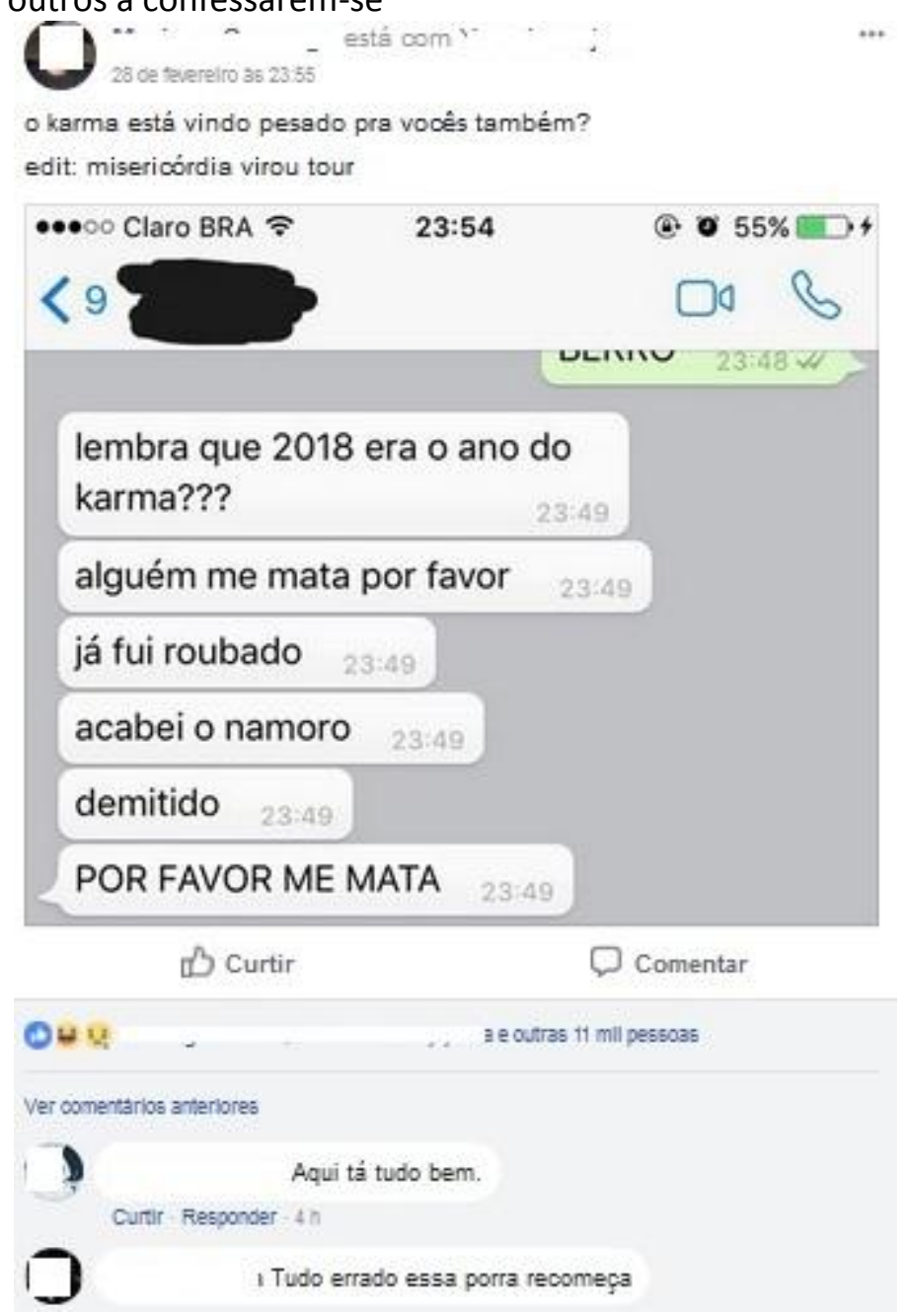

Neste recorte, vê-se que a postagem principal consiste em uma indagação: "O karma está vindo pesado para vocês?", associado a uma imagem retirada do aplicativo de comunicações via mensagens WhatsApp. Vê-se que a ideia desta postagem não centra-se em produzir uma narrativa de si, uma confissão de algo, mas em convidar os outros, estimula-los a examinarem a si mesmos. Este processo compõe-se quase como uma herança operatória de exagoreusis, desta possibilidade de confessar-se constantemente, sobre os desejos mais íntimos se necessário, o grupo confere um espaço de acolhimento, proteção, aconselhamentos e purificação. Todavia, se no ato de exagoreusis o sujeito encontrava-se convidado a confessar-se sobre seus desejos pecaminosos e desvios, em relação a um quadro de referências (FOUCAULT, 2014a), aqui as confissões são direcionadas, querem saber de algo específico neste post, algo mais parecido com as ferramentas de exame do Outro operadas pela lógica das ciências modernas, como as ciências da vida, jurídicas e da mente, em que inquirem o Outro a falar de aspectos específicos sobre si (FOUCAULT, 2015; 2007).

Este ato de direcionamento do narrar a si, de estabelecer uma confessionalidade e mantê-la registrada, via o inquirir o Outro, leva também à produção deste espaço como um arquivo, um sistema organizado de dados. Um herbário em que essas vidas, estes corpos, são organizados de acordo com seus desejos, expressos e registrados em seus atos de confessionalidade. Uma antologia das existências, que só tornam-se possíveis, ou melhor, atualizáveis, à medida que são "[...] Vidas de algumas linhas" (FOUCAULT, 2002, p.89), dispostas neste arquivo. Um herbário que organiza-se de acordo com as organizações documentais das ciências jurídicas, ao administrar seus casos e suas vidas. Talvez, um tribunal dos corpos do Vale, onde a produção do vale não se limita apenas a um espaço, mas também como um arquivo, opera por meio do convite às confissões, em que agencia-se estes desejos. 
Neste tocante, ressaltamos que a produção de arquivos da-se em uma relação dos corpos visíveis e enunciáveis. Assim, o grupo como espaço, organiza as experiencialidades e disposições dos corpos e pauta-se em um regime das visibilidades. Uma produção de um panóptico, que coloca os corpos em regimes de controle de seus movimentos, àqueles que instaura-se uma política em que todos encontram-se sob vigilância e visibilidade- uns para com os outros- e ao mesmo tempo estas visibilidades requerem movimentações, luzes e sombras (FOUCAULT, 2014b). Assim, poderíamos lançar mão da metáfora e pensar as luzes como os convites às confissões, o movimento como o ato de confessar e, as sombras, os decalques que os corpos deixam com seus comentários.

Assim, a produção de micro-histórias, quando não provém inicialmente de uma pulsão das vontades que colocam um corpo em excitação, para a produção de uma postagem inicial com enfoque na confissão, pode ser movimentada pelos convites às confissões, agencia, mobiliza, deriva e desloca outras formas de confessar. Destarte, os convites às confissões deslocam a seletividade do que confessar que encontra-se na pulsão de um corpo, partindo de suas vontades - reguladas, mediadas e estimuladas por um regime normativo vigente para um agenciamento dessas vontades, para que estas não sejam uma publicação inicial, mas sim, um comentário - mobilizando a possibilidade da produção de um arquivo, de acordo com as verdades confessas via o convite as confessionalidades.

\section{DESEJOS AGENCIADOS: RESPONDENDO A CONVITES}

Ao voltarmos nosso olhar às tecnologias da confessionalidade, presenciadas em operação no Vale, deparamo-nos com publicações realizadas compostas por micro-historiografias de $\mathrm{si}$, de modo que este corpo compõe-se ao contar sua micro-história. Também presenciamos publicações que mobilizam-se convidando o Outro a confessar-se sobre uma determinada temática. Ambas formas de operação, dão-se por uma pulsão, por uma vontade, que aquele corpo tem de fazer-se em redes. No primeiro caso, o corpo encontra-se excitado e, mobiliza a sua vontade a narrar-se, confessar-se, sobre um acontecimento de sua história. No segundo caso, o corpo encontra-se excitado a convidar o outro a falar de si, de suas vontades e de seus desejos.
Assim, um (im)pulsionar das vontades encontrase em interação.

Para Friedrich Nietzsche (1974) as vontades são a própria vida, ela guia-nos nas leituras de mundo e na produção de nosso modo de existência. Assim, as vontades podem levarnos a excitação delas, à busca de novos territórios, disputas, conquistas, no fazer-se outro continuamente; ou, no esvaziamento destas vontades, que substituem-se por outras à medida que renuncia-se a suas singularidades e aos seus prazeres. Assim, nossas vontades sempre encontram-se tracionadas, a encher-se ou esvaziar-se. Esta mobilização da vontade sempre nos faz um existir de outra forma, de uma forma outra, à medida que negocia-se com seu deslocamento.

Neste tocante, pode-se pensar a narrativa de si como uma balizadora das vontades, visto que no processo de exame de si é criadora de sentidos, significados e percursos. Este processo do exame de si, não é dado em uma liberdade, em um corpo em si, mas sim atravessados em sua contingência, localizada em práticas culturais e modos de subjetivação que atravessam os corpos que narram-se, confessam-se (FOUCAULT, 2015; 2014a; 2014b). Neste tocante, as práticas culturais atravessam os corpos com tecnologias de poder, que estabelecem e reverberam estatutos de verdade, à medida que os corpos em contato com estes, negociam sentidos e significados, via tecnologias de resistência, reiterando ou rarefazendo estas tecnologias de poder - este processo é chamado de modo de subjetivação, ou seja, o processo de (des)(re)produção de uma subjetividade que é negociado neste continuum. Assim, o exame de si cria percursos, trajetórias para as vontades, visto que o voltar o olhar a si - muitas vezes sob as narrativas dos Outros - faz com que os corpos munam-se de tecnologias de resistência, ou abram-se às tecnologias de poder.

De tal modo, o processo de exame de si, do narrar a si e confessar-se, é atravessado pelas vontades, que é mobilizada por tecnologias de poder e tecnologias de resistência. $O$ convite à confissão, neste sentido, é um espaço de abertura, que estimula o exame de si e, ao mesmo tempo utiliza mecanismos de poder para guiar as confissões. É um agenciamento das vontades a confessarem-se, podendo coloca-las em movimento levando à confissão, ou não.

Vemos por exemplo, uma postagem que parte de um convite à confissão e, que agencia 
vontades a confessarem-se, na figura abaixo

(FIGURA 3):

Figura 3. Respostas as confissões

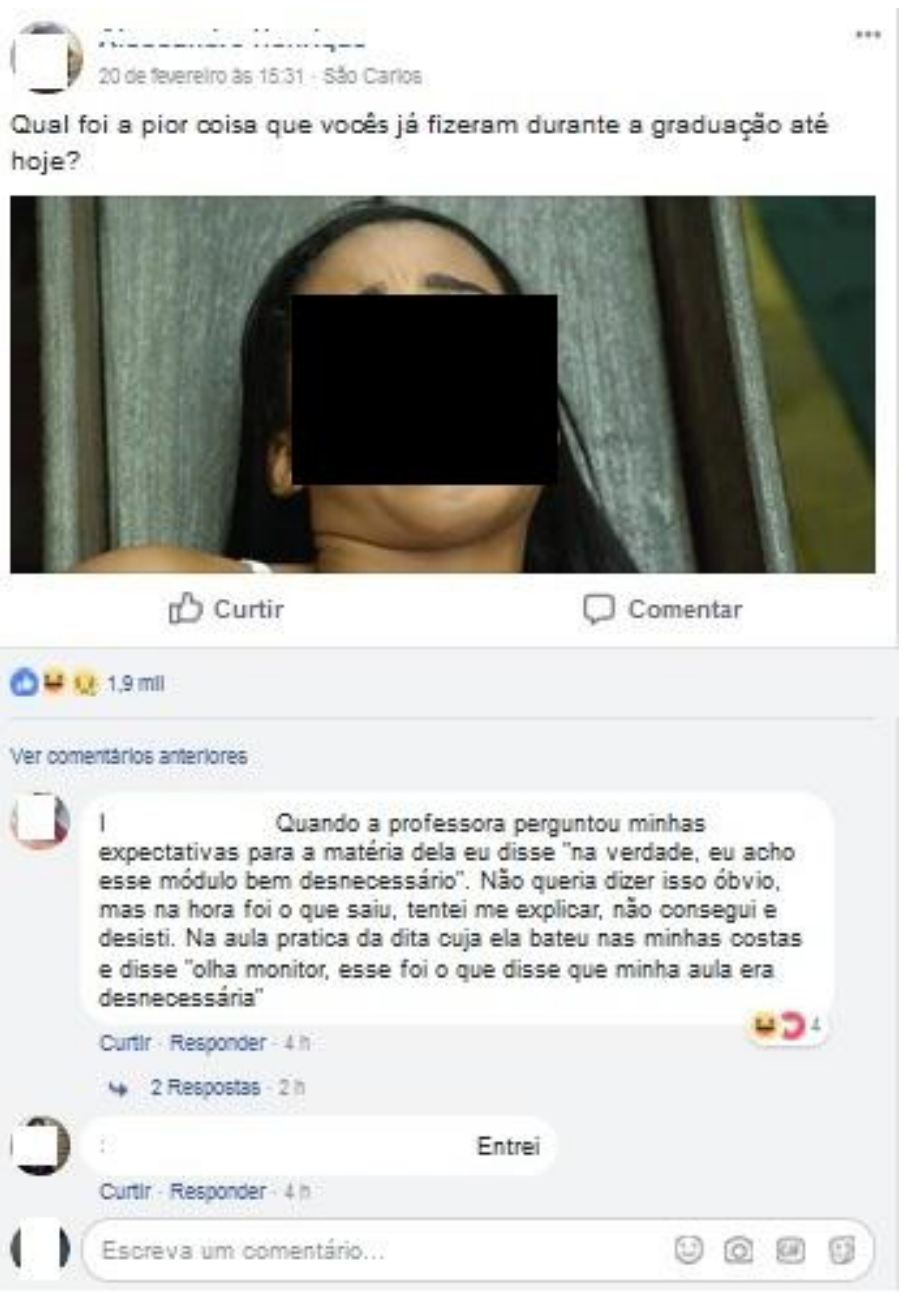

Nesse recorte, é possível vermos que o convite à confissão também opera pela convocação das vontades a narrarem suas microhistórias. Estas micro-historiografias dão-se em textos curtos, em reações ou até mesmo em uma palavra, como vemos neste caso, em que o corpo confessa que a "a pior coisa que já fez na graduação" foi o fato de ter entrado. Neste excerto a confissão de uma palavra arrasta consigo a produção de uma verdade sobre este corpo. Enquanto outros criam um texto curto sobre sua experiencialidade. Nestes três sentidos - reagir ao convite à confissão (com as ferramentas de curtir, amei, risos, uai, choro e raiva), no produzir um texto curto ou no confessar-se com uma única palavra - os corpos que fizeram confessos consistem naqueles em que suas vontades foram direcionadas ao ato de narrar-se, confessar-se. Assim, a confissão envolve o agenciamento das vontades, sendo este agenciamento considerado aquilo que coloca as vontades a agirem - a confessarem-se ou não.

\section{CONSIDERAÇÕES CONFESSAS}

Confessamos, neste ensaio em que trazemos um primeiro movimento de traçar considerações sobre a tecnologia das confessionalidades, um modo de produção de corpo nas virtualidades. Vemos o operar, no Vale, o convite ao narrar a si como uma agência de desejos, em que as narrativas são registradas no grande arquivo do-no "ciberespaço". Vê-se que esta tecnologia confessional opera como um modo de composição de si e de dizer a verdade sobre si, estabelecendo uma suposta coerência entre o que é registrado no grupo e o modo de existência deste corpo. Esta tecnologia apresenta outras configurações de (auto)disciplinamento do corpo, de modo que os integrantes deste agrupamento agem: a) Confessando microhistoriografias de si, como publicação inicial 
movida por sua vontade, atravessada por regulamentações, estabelecendo uma ideia de coerência entre o narrado e o vivido; b) Convidando outros a confessarem suas vontades, à medida que também apresenta sua posição de sujeito; c) Respondendo aos convides da confissão, por meio de comentários guiados pela postagem.

Estas três operações são separadas para um fim de compreensão desta tecnologia, mas reconhecemos que estas ocorrem concomitantemente e engendradas, compondo um regime de produção dos corpos que narramse, deixam-se marcados e registrados no movimento de suas vontades. Este regime de composição envolve a possibilidade de enunciar a si e, assim, envolve a produção de um panopticismo, uma regulamentação das visibilidades. Destarte, poderíamos lançar mão da metáfora do panóptico apresentada na obra Vigiar e Punir de Michel Foucault (2014b), considerando as luzes, o movimento e as sombras. As luzes seriam os convites às confissões, o movimento como 0 ato de confessar e, as sombras, os decalques que os corpos deixam com seus comentários - um corpo que produz-se na virtualidade, produz-se no deslocar-se neste regimento.

Este ainda é um movimento inicial, um relato experimental da teorização que encontrase em curso, analisando as práticas sociais no Vale, no que tocam o que tratamos como uma tecnologia das confessionalidades. Como um trabalho em curso, este tende-se a (des)(re)calibrar-se, bem como suscitar inspirações e convites para o pensar esta tecnologia.

\section{REFERÊNCIAS}

ARTIÉRRES, P. Dizer a atualidade: o trabalho de diagnóstico em Michel Foucault. In: GRÓS, F. Foucault: a coragem da verdade. São Paulo: Parábola Editorial, 2004. p. 15-38.

FOUCAULT, M. História da sexualidade I: a vontade de saber. 3 ed. São Paulo: Paz e Terra, 2015.

FOUCAULT, M. As técnicas de si. In: FOUCAULT, $M$. Ditos e escritos volume IX - Genealogia da ética, subjetividade e sexualidade. Rio de Janeiro: Forense Universitária, 2014a. p. 265 -296
FOUCAULT, M. Vigiar e punir: nascimento da prisão. 42 ed. Petrópolis: Vozes, 2014b.

FOUCAULT, M. El poder psiquiátrico. Buenos Aires: Fondo de la Cultura Econômica, 2007.

FOUCAULT, M. A vida dos homens infames. FOUCAULT, M. (Orgs). 0 que é um autor? Lisboa: Editora Vega, 2002. p. 89-128.

FOUCAULT, M. As palavras e as coisas: uma arqueologia das ciências humanas. 8. ed. São Paulo: Marins Fontes, 1999.

LÉVY, P. O que é o virtual? São Paulo: Ed. 34, 1996.

MARTINS, C. J. Michel Foucault: filosofia como diagnóstico do presente. 1998. Dissertação (Mestrado em Filosofia) - Universidade Estadual de Campinas, Campinas, 1998.

NIETZSCHE, F. Obras incompletas. São Paulo: Abril Cultural, 1974.

Recebido para publicação em 16/08/2018

Revisado em 10/09/2018

Aceito em 11/09/2018 